\title{
Hemograma, Sódio, Potássio, Cálcio, Osmolalidade e Viscosidade durante Angiocardiografia Pediátrica com Ioxaglato
}

\author{
Mauro Regis Silva Moura, Flávio Leboute, Carlos Antonio Mascia Gottschall \\ PortoAlegre, RS
}

\begin{abstract}
Objetivo - Os meios de contraste (MC) introduzem alterações em alguns parâmetros sangüíneos, adquirindo, assim, mais importância na angiocardiografia pediátrica.

Métodos - Estudamos a presença e a severidade das mudanças no hematócrito, hemoglobina, leucócitos, sódio, potássio, cálcio, osmolalidade e viscosidade, em 35 crianças submetidas a angiocardiografia com ioxaglato, identificando, também, as variáveis independentes responsáveis por essas alterações. As amostras sangüineas foram colhidas no início do procedimento (S1), no fim (S2) e $2 \mathrm{~h}$ após (S3).

Resultados - Hematócrito: $S 1=47,3 \pm 6,9 \%$; $S 2=$ $40,7 \pm 7,4 \%(p<0,001)$ (relacionado com o ioxaglato $r=0,37, p<0,05)$. Hemoglobina: $S 1=15 \pm 2,1 \mathrm{~g} \%$; $S 2=$ 13,2 $\pm 2,4 g \%$ ( $p<0,001)$. Leucócitos: $S 1=7940 \pm 3040$

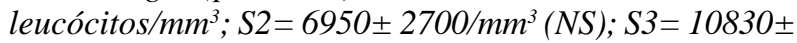
4690, ( $p<0,001)$. Identificamos a duração do procedimento $(r=0,38, p<0,05)$ e o volume total de soro glicosado $(r=0,49, p<0,05)$. Sódio: $S 1=134,5 \pm 0,4 m E q / L ; S 2=$ $130,7 \pm 0,4 m E q / L(p<0,001)$ relacionado à solução glicosada $(r=0,61, p<0,01)$. Potássio: $S 1=4,22 \pm$ $0,45 \mathrm{mEq} / \mathrm{L} ; \mathrm{S} 2=3,83 \pm 0,4 \mathrm{mEq} / \mathrm{L}(p<0,001)$. Nenhuma variável foi isolada. Cálcio; $S 1=9,13 \pm 1,03 \mathrm{mg} \% ; S 2=$ $8,4 \pm 0,91 \mathrm{mg} \%$ (relacionado ao ioxaglato $r=0,43$, p<0,01). Osmolalidade: $S 1=293,3 \pm 12,5 \mathrm{mOsm} / \mathrm{kg} ; \mathrm{S} 2=$ $300,6 \pm 13,3 \mathrm{mOsm} / \mathrm{kg}(p<0,001)$. Nenhuma das variáveis independentes foi isolada. Viscosidade: $S 1=3,36 \pm 0,81$; $S 2=3,09 \pm 0,74(p<0,01) ; S 3=3,87 \pm 0,89, p<0,001$ (devido a uma regressão linear indireta com o $M C$ ).

Conclusão - Variações significativas nas variáveis dependentes medidas foram observadas durante e após o procedimento. $O$ uso do ioxaglato foi parcialmente relacionado a mudanças no hematócrito/hemoglobina, cálcio total e viscosidade mas não as das variáveis restantes.
\end{abstract}

Palavras-chave: meios de contraste, angiocardiografia, cardiologia pediátrica

\section{Blood Cell Count, Sodium, Potassium, Cal- cium, Osmolality and Viscosity, During Pedi- atric Angiocardiography with Ioxaglate}

Purpose - Children's blood changes during angiocardiography may not be only due to the contrast media $(C M)$.

Methods - We studied the presence and severity of changes in those parameters in 35 pediatric patients undergoing angiocardiography with ioxaglate aiming to identify independent variables responsible for those changes. Blood samples were taken at the beginning of the procedure (S1), at the end (S2) and two hours later (S3).

Results - Hematocrit: $S 1=47.3 \pm 6.9 \% ; S 2=40.7 \pm$ $7.4 \%(p<0.001)$, (related to the $C M$ volume $r=0.37$, $p<0.05)$. Hemoglobin: $S 1=15 \pm 2.1 \mathrm{~g} \% ; S 2=13.2 \pm 2.4 \mathrm{~g} \%$ ( $p<0.001)$, and $S 3=12.7 \pm 2.5 \mathrm{~g} \%$ (NS). White blood cell count $:$ S1 $=7940 \pm 3040$ leukocytes $/ \mathrm{mm}^{3} ; S 2=6950 \pm$ $2700 / \mathrm{mm}^{3}$ (NS); $S 3=10830 \pm 4690$ leukocytes $/ \mathrm{mm}^{3}$, $(p<0.001)$. Procedure duration $(r=0.38, p<0.05)$ and $5 \%$ glucose fluid given between $S 2$ and $S 3(r=0.49, p<0.05)$ were isolated. Sodium: $S 1=134.5 \pm 0.4 \mathrm{mEq} / \mathrm{L} ; \mathrm{S} 2=$ $130.7 \pm 0.4 \mathrm{mEq} / \mathrm{L}(p<0.001)$ (due to $5 \%$ glucose fluid in jected, $r=0.61, p<0.01)$. Potassium: $S 1=4.22 \pm 0.45 \mathrm{mEq} / \mathrm{L}$, $S 2=3.83 \pm 0.4 \mathrm{mEq} / \mathrm{L}(p<0.001)$. Calcium: $S 1=9.13 \pm$ $1.03 \mathrm{mg} \% ; S 2=8.4 \pm 0.91 \mathrm{mg} / \mathrm{dL}$. (related to the $C M$, $r=0.43, p<0.01$.) Osmolality: $S 1=293.3 \pm 12.5 \mathrm{mOsm} / \mathrm{kg}$; $S 2=300.6 \pm 13.3 \mathrm{mOsm} / \mathrm{kg}(p<0.001)$. Viscosity: $S 1=$ $3.36 \pm 0.81 ; S 2=3.09 \pm 0.74(p<0.01) ; S 3=3.87 \pm 0.89, p<0.001$. There was an indirect linear regression with the $C M$.

Conclusion - There were profound differences among the dependent variables observed but the ioxaglate was partially related to changes in hematocrit/ hemoglobin, total calcium and viscosity. We failed to demonstrate significant regression coefficient between CM and changes in leukocytes, sodium, potassium, and osmolality.

Key-words: contrast media, angiocardiography, heart catheterization, pediatric cardiology

Arq Bras Cardiol, volume 70 (n 4), 257-264, 1998

Instituto de Cardiologia do Rio Grande do Sul/Fundação Universitária de Cardiologia

Correspondência: Mauro Regis S. Moura - Instituto de Cardiologia do RS/FUC Unidade de Pesquisa - Av. Princesa Isabel, 395 - 90620-001 - Porto Alegre, RS Recebido para publicação em 7/1/98

Aceito em 4/2/98
Os meios de contraste (MC) são formulações largamente utilizadas na angiocardiografia. Contudo, na medida que apresentam propriedades físico-químicas diferentes das do sangue, podem, ocasionalmente, trazer algum risco 
durante os procedimentos de cateterização cardíaca ${ }^{1}$. Isto é particularmente verdadeiro, quando se trata de estudo hemodinâmico em crianças, pois elas apresentam menores volumes sangüíneos, menor massa nos órgãos de impacto, vasos e câmaras cardíacas de paredes delgadas e, com freqüência, estão funcionalmente comprometidas por cardiopatias congênitas ${ }^{2}$.

Poucos estudos descrevem os efeitos dos MC durante a angiocardiografia pediátrica. A maior parte deles descreve alterações em algumas variáveis, ocorridas imediatamente após a injeção do MC, quando o seu alto nível no sangue é comumente considerado responsável pelas mudanças. Outros preocuparam-se com comparações entre diferentes tipos de $\mathrm{MC}^{3-21}$, mas, nenhum foi delineado para avaliar a interferência de outras variáveis presentes durante a cateterização cardíaca.

Propusemo-nos avaliar a presença e a severidade das alterações nas seguintes variáveis dependentes: hematócrito, hemoglobina, leucócitos, sódio, potássio, cálcio, osmolalidade e viscosidade durante angiocardiografia com ioxaglato e, como objetivo secundário, determinar quais das variáveis independentes, introduzidas durante o procedimento, foram responsáveis por mudanças significativas nas médias das variáveis dependentes.

Foram consideradas variáveis independentes todas as condições específicas, rotineiramente, associadas com cateterização cardíaca em crianças em nosso laboratório, ou sejam: duração do procedimento, volume do MC injetado, número de injeções do $\mathrm{MC}$, volume de soro glicosado a $5 \%$ infundido durante e após o procedimento, volume de fluídos injetados durante e após o exame, tempo de jejum antes do exame e tempo total de jejum.

\section{Métodos}

Delineamos um estudo observacional, prospectivo, analítico, de dados pareados, para uma coorte de 35 crianças (22 meninos, 13 meninas), com idades entre 0-6 (média $2,42 \pm 1,61$ ) anos, e um peso médio de $11,31 \pm 5,13 \mathrm{~kg}$, encaminhadas ao procedimento angiocardiográfico devido a cardiopatias congênitas de uma forma seqüencial.

A tabela I mostra todas as crianças estudadas e as variáveis independentes observadas: idade, peso, tempo de jejum antes do procedimento, duração do procedimento, número de injeções, volume total de $\mathrm{MC}(\mathrm{em} \mathrm{ml}$ e $\mathrm{ml} / \mathrm{kg})$ injetado em cada caso, e o volume de soro glicosado infundido durante e após o exame. A informação acerca da quantidade de soro glicosado a $5 \%$ infundido foi coletada somente nos últimos 21 casos após um estudo piloto dos primeiros 12 casos. Análise de regressão múltipla foi aplicada nestes 21 casos.

As crianças foram levadas à sala de hemodinâmica com um jejum mínimo de $6 \mathrm{~h}$ (média $11,01 \pm 2,05 \mathrm{~h}-1^{\circ}$ procedimento matutino), pré medicadas com cloridrato de morfina $0,2 \mathrm{mg} / \mathrm{kg}$ e sulfato de atropina $0,01 \mathrm{mg} / \mathrm{kg}$, e todas submetidas a anestesia geral com entubação orotraqueal e ventiladas num ambiente de $\mathrm{O}_{2}$ a $100 \%$, com isofluorane 0,5-1\%. Uma veia periférica foi puncionada para infundir solução glicosada a 5\%. O cateter (usualmente um NIH 7F) foi introduzido pela técnica de Seldinger, a partir da veia femoral até o átrio direito (AD).

A $1^{\mathrm{a}}$ amostra sangüínea $(\mathrm{S} 1)$ e a $2^{\mathrm{a}}(\mathrm{S} 2)$ foram coletadas no AD. A $3^{\mathrm{a}}$ (S3), foi obtida por punção venosa $2 \mathrm{~h}$ após o fim do exame, antes do início da alimentação oral. Todas amostras foram coletadas com cuidado, com objetivo de evitar a contaminação do sangue por outras substâncias. As amostras foram prontamente examinadas em nosso laboratório de patologia clínica.

O MC usado foi o ioxaglato, um dímero iônico de baixa osmolalidade, considerado um dos mais adequados para angiocardiografia pediátrica ${ }^{5,12,17,22}$, contendo $19,6 \%$ de ioxaglato de sódio e 39,3\% de ioxaglato de meglumina, cerca de $580 \mathrm{mOsm} / \mathrm{kg}$, 6 átomos de iodo para cada par de íons (razão de iodo igual a 3), conteúdo de iodo igual a $320 \mathrm{mg} / \mathrm{ml}$, concentração de iodo de $32 \%$ e concentração da solução de $59 \%$. Seu conteúdo de sódio é de $150 \mathrm{mEq} / \mathrm{L}$, viscosidade de 7,5 cps (5,8 em relação à água) é aditivado com $0,2 \mathrm{mg} / \mathrm{ml}$ de calciedetato de sódio ${ }^{24}$.

Sódio e potássio foram medidos por espectrofotometria e são expressos em mEq/L. O cálcio total foi obtido pelo metiltimol e está expresso em mg\%. A osmolalidade foi obtida pelo Advanced Osmometer $3 \mathrm{~W}$ e seus resultados são apresentados como mOsm $/ \mathrm{kg}$. A viscosidade foi determinada pelo viscosímetro de Hess e sua unidade é expressa em valores absolutos. Os leucócitos pelo ContCelCounter D2. O hematócrito pelo IEC modelo MB, e a

\begin{tabular}{|lllllllll}
\hline \multicolumn{7}{|c|}{ Tabela I - Dados estatísticos das variáveis independentes } \\
\hline
\end{tabular}




\begin{tabular}{|c|c|c|c|c|c|c|c|c|}
\hline & Unidade & $\mathrm{n}$ & $\begin{array}{c}\text { S1 } \\
\text { Início }\end{array}$ & $\begin{array}{l}\text { S1 x S2 } \\
\text { Anova }\end{array}$ & $\begin{array}{l}\mathrm{S} 2 \\
\text { Fim }\end{array}$ & $\begin{array}{l}\text { S2x S3 } \\
\text { Anova }\end{array}$ & $\begin{array}{c}\text { S3 } \\
\text { 2h após }\end{array}$ & $\begin{array}{r}\text { S1 x S3 } \\
\text { Anova }\end{array}$ \\
\hline Hematócrito & $\%$ & 35 & & & & & & \\
\hline Média $\pm 1 D P$ & & & $47,3 \pm 6,9$ & $\mathrm{~S}^{* * * *}$ & $40,7 \pm 7,4$ & NS & $39,7 \pm 7,7$ & $\mathrm{~S}^{* * * *}$ \\
\hline Amplitude & & & $32-61$ & & $26-57$ & & $24-56$ & \\
\hline Hemoglobina & $\mathrm{g} \%$ & 35 & & & & & & \\
\hline Média $\pm 1 D P$ & & & $15 \pm 2,1$ & $\mathrm{~S} * * *$ & $13,2 \pm 2,4$ & NS & $12,7 \pm 2,5$ & $\mathrm{~S}^{* * *}$ \\
\hline Amplitude & & & $9,3-19$ & & $7,9-18,4$ & & $7,4-17,6$ & \\
\hline Leucócitos & cells $/ \mathrm{mm}^{3}$ & 35 & & & & & & \\
\hline Média $\pm 1 D P$ & & & $7937 \pm 3036$ & NS & $6950 \pm 2705$ & $\mathrm{~S}^{* *}$ & $10826 \pm 4689$ & $\mathrm{~S}^{* *}$ \\
\hline Amplitude & & & $2200-15300$ & & $2500-14700$ & & $3800-25700$ & \\
\hline Neutrófilos & & 21 & & & & & & \\
\hline Média $\pm 1 D P$ & & & $3051-1545$ & NS & $2877 \pm 1388$ & $\mathrm{~S} * * *$ & $4357 \pm 1758$ & $\mathrm{~S}^{* * *}$ \\
\hline Amplitude & & & $793-5883$ & & $720-5518$ & & $1026-7956$ & \\
\hline Linfócitos & & 21 & & & & & & \\
\hline Média $\pm 1 D P$ & & & $3988 \pm 2191$ & NS & $3369 \pm 1769$ & $\mathrm{~S}^{* *}$ & $4461 \pm 1622$ & NS \\
\hline Amplitude & & & $1100-8246$ & & $920-7714$ & & $1740-7475$ & \\
\hline Sódio & $\mathrm{mEq} / \mathrm{l}$ & 35 & & & & & & \\
\hline Média $\pm 1 D P$ & & & $134,6 \pm 3.4$ & $\mathrm{~S}^{* * * *}$ & $130,7 \pm 4,3$ & $\mathrm{~S}^{* * *}$ & $134,3 \pm 3,7$ & NS \\
\hline Amplitude & & & $118-141$ & & $117-138$ & & $122-142$ & \\
\hline Potássio & $\mathrm{mEq} / \mathrm{l}$ & 35 & & & & & & \\
\hline Média $\pm 1 D P$ & & & $4,22 \pm 0,45$ & $\mathrm{~S}^{* * *}$ & $3,83 \pm 0,41$ & $\mathrm{~S}^{* * *}$ & $4,27 \pm 0,53$ & NS \\
\hline Amplitude & & & $3,3-5,7$ & & $3,1-4,8$ & & $3,3-5,7$ & \\
\hline Cálcio & $\mathrm{mg} \%$ & 35 & & & & & & \\
\hline Média $\pm 1 D P$ & & & $9,13 \pm 1,02$ & $\mathrm{~S}^{* * *}$ & $8,4 \pm 0,91$ & $\mathrm{~S}^{* * *}$ & $9,43 \pm 0,98$ & NS \\
\hline Amplitude & & & $6,9-11,2$ & & $6,7-10,4$ & & $7,4-11,1$ & \\
\hline Osmolalidade & mOsm/kg & 35 & & & & & & \\
\hline Média $\pm 1 D P$ & & & $293,4 \pm 12,5$ & $\mathrm{~S} * * *$ & $300,6 \pm 13,3$ & $\mathrm{~S}^{* * *}$ & $286,6 \pm 20,1$ & $\mathrm{~S}^{* *}$ \\
\hline Amplitude & & & $274,4-333,7$ & & $284,4-338,2$ & & $235,2-353,9$ & \\
\hline Viscosidade & absoluta & 35 & & & & & & \\
\hline Média $\pm 1 D P$ & & & $3,36 \pm 0,81$ & $\mathrm{~S} * *$ & $3,09 \pm 0,74$ & $\mathrm{~S}^{* * *}$ & $3,87 \pm 0,89$ & $\mathrm{~S}^{* * *}$ \\
\hline Amplitude & & & $2,3-5,8$ & & $2-5,3$ & & $2,4-6,5$ & \\
\hline
\end{tabular}

hemoglobina pelo Hemoglobinometer Coulter D2.

As médias dos dados pareados foram comparadas por análise de variância. Um valor de $\mathrm{p}<0,05$ foi considerado significante. Várias regressões lineares simples foram usadas para identificar as variáveis independentes, que influenciaram as alterações nas variáveis dependentes sob observação. A análise de regressão múltipla foi aplicada nos últimos 21 casos, nos quais dispúnhamos do controle do volume da solução glicosada a 5\% infundida, assim como a contagem diferencial dos leucócitos (tab. I). Usamos o programa statgraphs 2.0 da Statistical Graphics Corporation, USA, 1986, com inclusão passo a passo anterógrada para detectar a presença de algum modelo multivariado e para confirmar os resultados das correlações encontradas pela utilização da regressão linear simples. Para avaliar as diferenças significativas encontradas entre as médias da S1, e da S2, (S1-S2), oferecemos como variáveis independentes: a duração do procedimento (minutos); o volume de solução glicosada a $5 \%$ infundida durante o exame em ml e $\mathrm{ml} / \mathrm{kg}$; o volume do MC em mle $\mathrm{ml} / \mathrm{kg}$; a soma dos volumes do MC e fluídos dados durante o exame em $\mathrm{ml} /$ $\mathrm{kg}$; tempo de jejum antes do procedimento; e tempo total de jejum.

Para explicar as eventuais alterações entre as variáveis dependentes que ocorressem entre o S2 e S3 obtida 2h após seu final, oferecemos: a duração do procedimento em minutos; volume do $\mathrm{MC} \mathrm{em} \mathrm{ml} / \mathrm{kg}$; e o total de soro glicosado dado após o exame em $\mathrm{ml} \mathrm{e} \mathrm{ml} / \mathrm{kg}$.

As alterações das médias das variáveis dependentes observadas entre S1 e S3, foram analisadas em função da: duração do procedimento em minutos; volume total de fluídos infundidos durante e após o procedimento em $\mathrm{ml} \mathrm{e} \mathrm{ml} /$ $\mathrm{kg} ; \mathrm{e}, \mathrm{MC} \mathrm{em} \mathrm{ml} / \mathrm{kg}$. A tabela I mostra os dados estatísticos das variáveis independentes.

\section{Resultados}

Não identificamos nenhum modelo multivariado. O uso da análise de regressão múltipla somente confirmou os dados encontrados com a regressão linear simples.

A tabela II mostra as médias das variáveis dependentes estudadas nos três momentos de coleta, e os resultados da ANOVA. O hematócrito que tinha um valor inicial de $47,3 \pm 6,9 \%$ caiu para $40,7 \pm 7,4 \%$ ao final do procedimento $(\mathrm{p}<0,001)$, permanecendo neste nível até $2 \mathrm{~h}$ após, quando colhemos a última amostra (NS). Esta redução de $14 \%$ no hematócrito é parcialmente explicada pelo volume total do MC usado ( $r=0,37, p<0,05)$. A hemoglobina mostrou-se uma variável interdependente do hematócrito com um coeficiente de Pearson quase perfeito $(r=0,96, p<0,001)$. Esta 


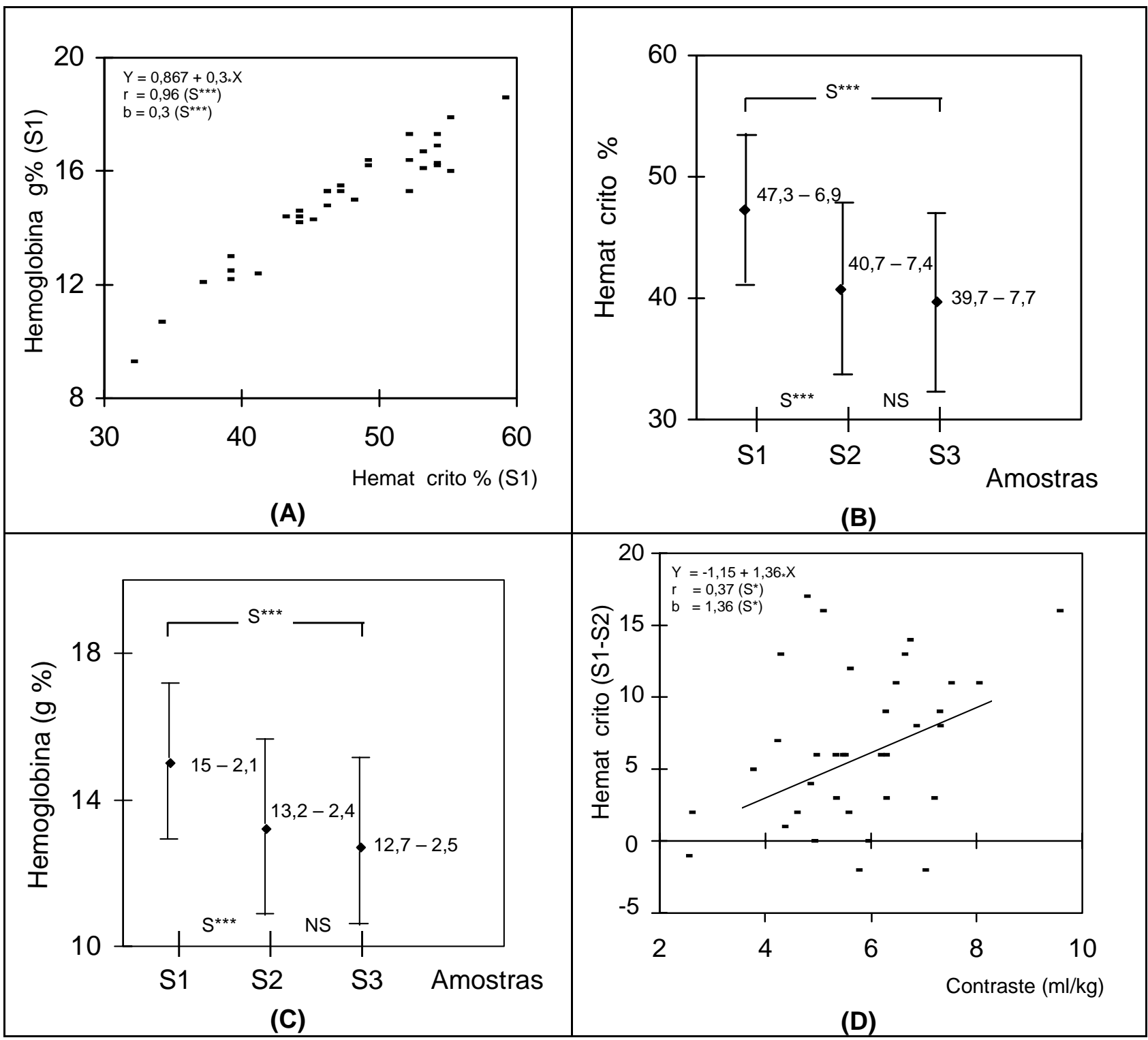

Fig. 1 - A) Regressão linear simples, entre hematócrito e hemoglobina ( $\mathrm{R}=0,96, \mathrm{p}<0,001, \mathrm{n}=35)$; $\mathrm{S} 1$ - $1^{\mathrm{a}}$ amostra; $\left.\mathrm{B}\right)$ hematócrito: média $\pm 1 \mathrm{SD}$; $\mathrm{S} * * *$ - $\mathrm{p}<0,001$; NS- não significante; S1,S2,S3- $1^{\mathrm{a}}, 2^{\mathrm{a}}$ e $3^{\mathrm{a}}$ amostras; C) hemoglobina: média $\pm 1 \mathrm{SD} ; \mathrm{S} * * *$ - p $<0,001$; NS- não significante; S1,S2,S3- $1^{\mathrm{a}}, 2^{\mathrm{a}}$ e $3^{\mathrm{a}}$ amostras; D) regressão linear simples entre ioxaglato e mudança no hematócrito (S1-S2) $(\mathrm{R}=0,37 ; \mathrm{p}<0,05)$.

correlação permaneceu imutável a despeito de todas as variáveis introduzidas durante o procedimento. Os valores da hemoglobina foram S1=15 $\pm 2,1 \mathrm{~g} \%$; S2 $=13,2 \pm 2,4 \mathrm{~g} \%$ (p<0,001) e S3=12,7 $\pm 2,5 \mathrm{~g} \%$ (NS) (fig. 1).

A média da contagem de leucócitos em S1 foi $7940 \pm$ 3040 leucócitos $/ \mathrm{mm}^{3}$ e emS2 6950 $\pm 2700 / \mathrm{mm}^{3}$ (NS). Contudo, $2 \mathrm{~h}$ após, encontramos uma média de $10830 \pm 4690$ leucócitos $/ \mathrm{mm}^{3},(\mathrm{p}<0,001)$. Razão que poderia ser explicada pela consistente correlação com o tempo despendido para a realização do procedimento $(\mathrm{r}=0,38, \mathrm{p}<0,05)$. Também encontramos correlação entre o sensível aumento dos leucócitos e o total de solução glicosada a $5 \%$ infundida no período $\mathrm{S} 2$ e $2 \mathrm{~h}$ após $\mathrm{S} 3$ ( $\mathrm{r}=0,49$, p <0,05 As diferenças das médias das amostras S1 e S3 também se correlacionaram, razoavelmente, com o tempo (minutos) de duração do procedimento $(r=0,56, p<0,001)$. As células responsáveis por essas alterações foram os neutrófilos segmentados e os linfócitos. Na figura 2 apresentamos as médias dos leucócitos bem como as correlações com a duração do procedimento e o volume de solução glicosada a $5 \%$ infundida.

Sódio, potássio e cálcio mostraram a mesma intensidade e sentido nas variações, mas por diferentes razões: eles caíram significativamente durante o procedimento (entre S1 e S2) e retornaram aos níveis iniciais $2 \mathrm{~h}$ após em S3. O sódio, de uma média inicial de (S1) 134,5 $\pm 0,4 \mathrm{mEq} / \mathrm{L}$ reduziu-se até (S2) 130,7 $\pm 0,4 \mathrm{mEq} / \mathrm{L}$ no fim do exame $(\mathrm{p}<0,001)$. Detectamos que esta correlação $(r=0,61, \mathrm{p}<0,01)$ teria ocorrido em vista do total de solução glicosada a $5 \%$ infundida $(14,34 \pm 11,48 \mathrm{ml} / \mathrm{kg})$ no decorrer do procedimento. Este volume infundido sofreu redução no intervalo entre as amostras S2 e S3 $(5,2 \pm 3,43 \mathrm{ml} / \mathrm{kg}$ ) (tab. I e II). O potássio foi de $4,22 \pm 0,45 \mathrm{mEq} / \mathrm{LemS} 1$, para $3,83 \pm 0,4 \mathrm{mEq} / \mathrm{L}(\mathrm{p}<0,001) \mathrm{em} \mathrm{S} 2$. 


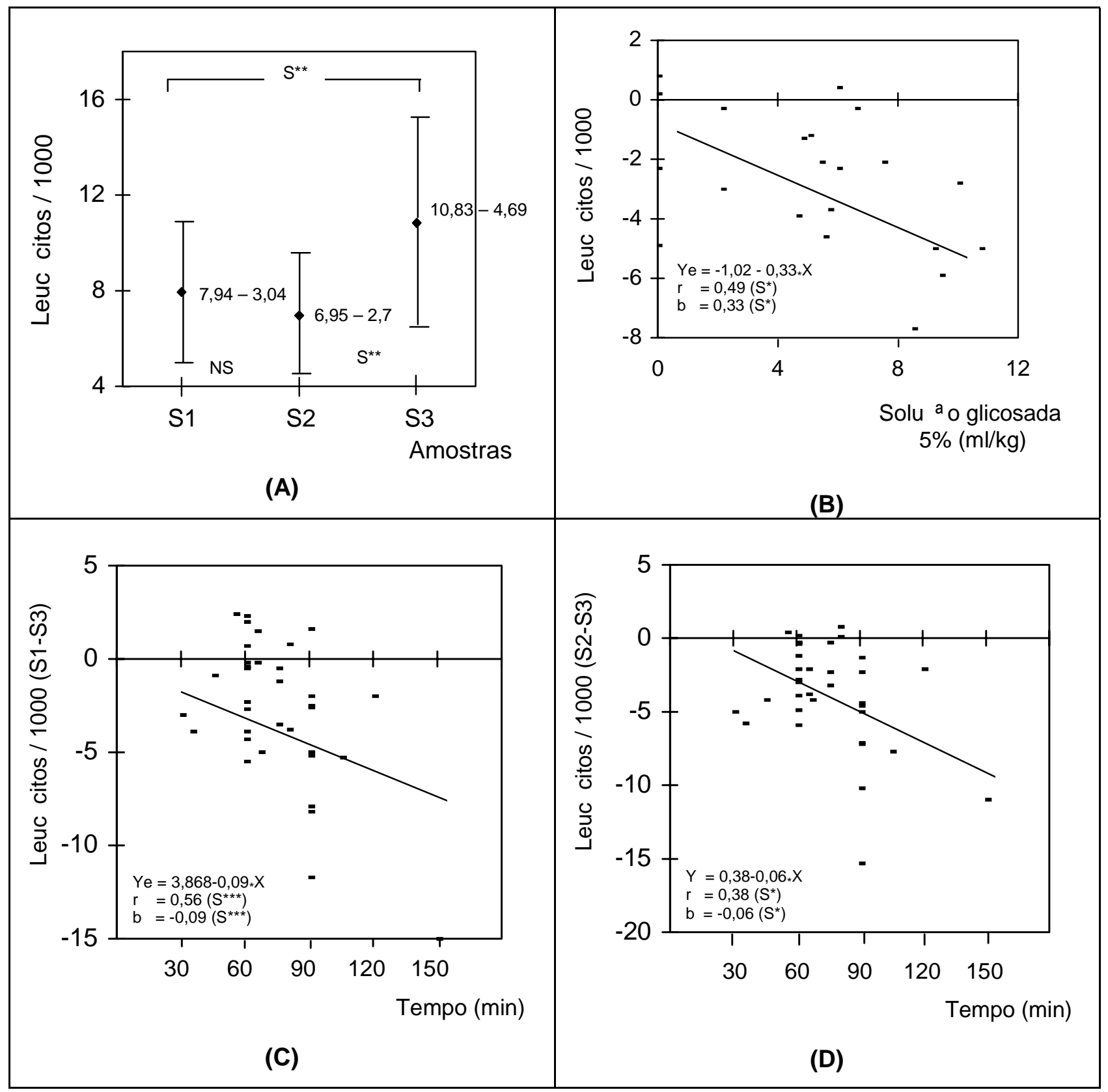

Fig. 2 - A) - Leucócitos: média $\pm 1 \mathrm{SD} ; \mathrm{NS}$ - não significante; $\mathrm{S}^{* *}$-p $<0,01 ; B$ ) regressão linear entre mudanças nos leucócitos (S2-S3) e solução glicosada 5\% (ml/kg); $\mathrm{S}^{*}$-p $<0,05 ;$ C) regressão linear simples entre variações nos leucócitos (S1-S3) e duração do cateterismo; $\mathrm{S} * * *$ - $\mathrm{p}<0,001$; D) regressão linear simples entre variações nos leucócitos (S2-S3) e duração do cateterismo; $S^{* * *}$ - $p<0,001$.

Não identificamos nenhuma variável independente responsável por esta variação. O valor médio do cálcio total foi de $9,13 \pm 1,03 \mathrm{mg} \%$ em S1, caindo para $8,4 \pm 0,91 \mathrm{mg} \% \mathrm{em} \mathrm{S} 2$ ao final do procedimento. A variação das médias entre S1 e S2 foi correlacionada ao volume do $\mathrm{MC}(\mathrm{r}=0,43, \mathrm{p}<0,01)$. A figura 3 mostra estas alterações iônicas e também o gráfico de regressão linear entre o decréscimo do cálcio (S1-S2) e o volume do $\mathrm{MC}(\mathrm{ml} / \mathrm{kg})$.

A osmolalidade subiu de $293,3 \pm 12,5 \mathrm{mOsm} / \mathrm{kg}$ (S1), para 300,6 $\pm 13,3 \mathrm{mOsm} / \mathrm{kg}(\mathrm{S} 2)(\mathrm{p}<0,001)$. Nenhuma variável independente foi isolada para explicar este incremento de $2,5 \%$. Duas horas após o fim do procedimento a osmola- lidade média foi 286,6 $\pm 20,1 \mathrm{mOsm} / \mathrm{kg}$ (S3); quando comparado com o $S 1$ e com $S 2$, encontramos significância ( $p<0,001)$, demonstrando que as alterações na osmolalidade devem ser uma resultante final de vários outros fatores, tais como: medida da osmolalidade ao final do procedimento (S2) que levou em média $74,1 \pm 23,1$ min para ser efetuado; solução glicosada diluindo o sódio sérico; e baixa osmolalidade do MC usado. O volume total de fluídos injetados (volume de MC injetado + volume de solução glicosada 5\%) mostrou um coeficiente de correlação $r=0,34, \mathrm{NS}$.

A viscosidade era em $\mathrm{S} 1=3,36 \pm 0,81, \mathrm{em} \mathrm{S} 2=3,09 \pm 0,74$ ( $<<0,01)$ e em S3, mostrou um aumento de 15,5\% $(3,87 \pm 0,89$, 


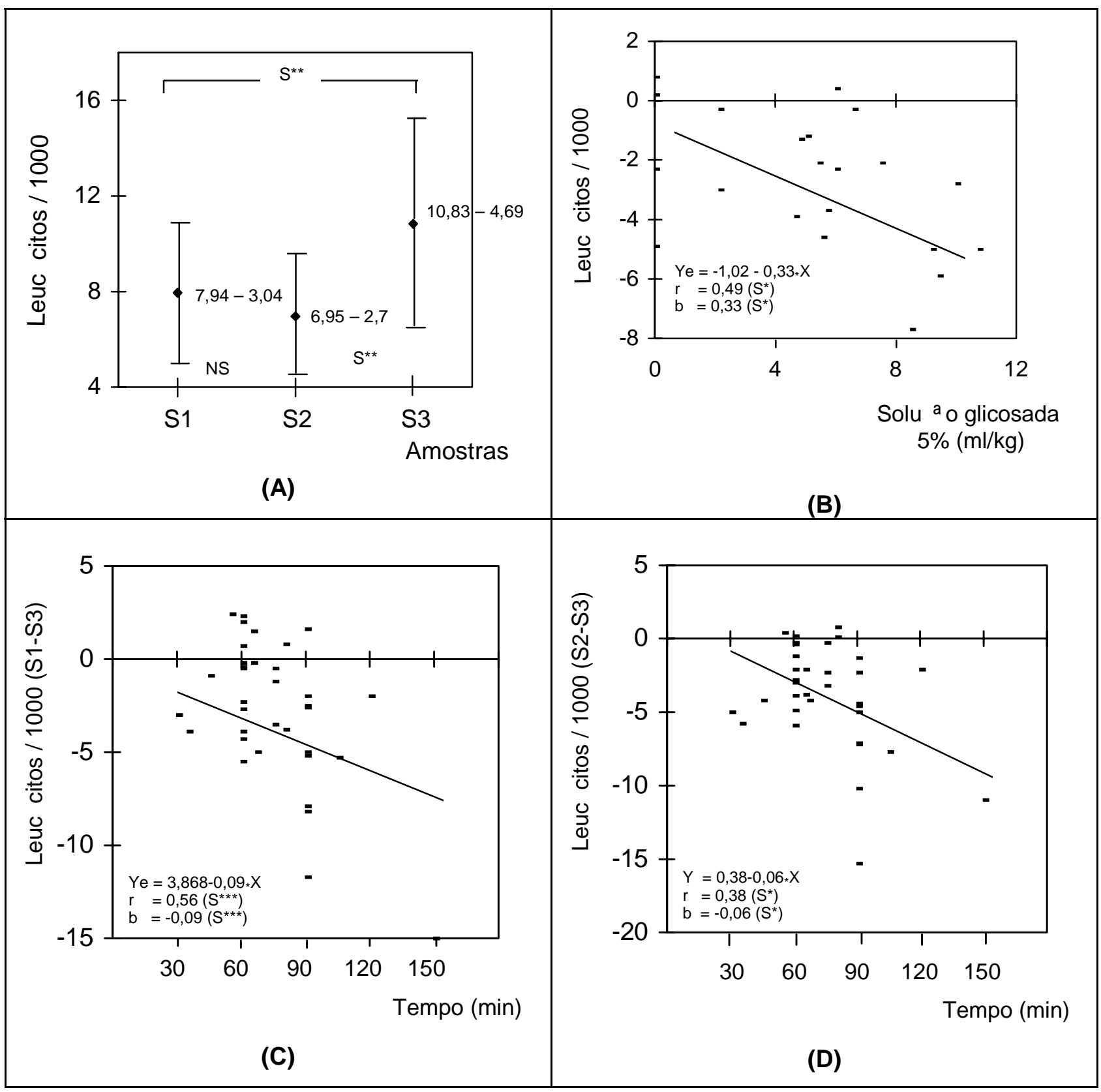

Fig. 3 -(A), (B), (C) - Média \pm 1SD do sódio, potássio e cálcio; NS- não significante; $\mathrm{S}^{* * *}$-p<0,001; D) regressão linear simples entre as médias de cálcio (S1-S2) e o MC; **-p<0,05; $\mathrm{S} * *-\mathrm{p}<0,01$.

$\mathrm{p}<0,001)$ sobre o valor $\mathrm{S} 1$. Encontramos um regressão linear indireta, ou inversa com o MC, ao se analisar as diferenças entre as médias $\mathrm{S} 1$ eS3 $(r=0,39$, $\mathrm{p}<0,05, \mathrm{n}=35)$. Desta forma, a viscosidade ao tempo da $\mathrm{S} 3$, só não alcançou níveis mais elevados devido à ação do MC, que atua de forma inversa por deixar o hematócrito (principal componente da viscosidade sangüínea) mais baixo (fig. 1B e 1D). Não identificamos nenhuma variável independente relacionada às diferenças entre as médias S1 e S2 e entre S2 e S3.

\section{Discussão}

Comumente, estudos sobre MC não consideram todas as variáveis (independentes), inerentes à da rotina de cada procedimento. Pretendíamos estudar a existência e amplitude de variação nas médias das variáveis dependentes e, também, verificar quais variáveis independentes responsáveis por tais alterações. O volume total de solução glicosada a 5\% infundida não foi controlado nos pacientes 1 a 14. Assim, a análise de regressão múltipla só pôde ser aplicada nos casos 15 a 35 (21 casos). Contudo todos os dados foram submetidos a ANOVA e múltiplas regressões lineares simples, com objetivo de confirmar os resultados da regressão múltipla. Como não se estabeleceu nenhum modelo multivariado, a regressão múltipla somente coincidiu com os resultados da regressão linear univariada. 
Confirmamos que o hematócrito e a hemoglobina eram variáveis interdependentes ${ }^{23}$, uma vez que ambos mostraram variações no mesmo sentido e com a mesma intensidade e um elevado coeficiente de correlação (r=0,96; fig. 1A). Suas médias caíram 14\% durante o procedimento (S1-S2), o que foi consistente com o já descrito na literatura ${ }^{3,5,11}$. Esta mudança é atribuída a desidratação dos eritrócitos e, secundariamente, ao aumento do volume plasmático, a partir doespaço extravascular. Oaumento da osmolalidade tem sido reconhecido como responsável por esses fenômenos ${ }^{3,11,24}$. A variável volume do ioxaglato injetado $(\mathrm{ml} / \mathrm{kg})$ demonstrou um coeficiente de correlação $(r=0,37 ; p<0,05)$ com o decréscimo das médias do hematócrito/hemoglobina $(\mathrm{ml} / \mathrm{kg}$ ) (fig. 1D). Esperávamos que o volume de soluto glicosado a $5 \%$, infundido durante o procedimento (média $14,3 \pm 11,48 \mathrm{ml} / \mathrm{kg}$ ), reduzisse o hematócrito/hemoglobina por efeito dilucional, no entanto, não foi encontrada correlação significativa. Uma vez que os valores das médias do hematócrito e hemoglobina permaneceram abaixo do nível inicial em S3, presumimos que perdas sangüíneas (que não foram controladas durante o procedimento), pudessem ser parcialmente responsáveis por esses achados.

Em 1981, Cumberland ${ }^{5}$ mostrou uma redução de $11 \%$ nos leucócitos após o uso de ioxaglato em 10 crianças. Confirmamos uma redução não significativa $(12,5 \%) \mathrm{em} \mathrm{S2}$ e um significativo e inesperado aumento $(56 \%)(\mathrm{p}<0,001) \mathrm{em} \mathrm{S3}$, quando se compararam os valores das médias entre a S2 e $\mathrm{S} 3$. Isto se deveu principalmente aos neutrófilos segmentados e aos linfócitos. A duração (minutos) do procedimento foi identificada como sendo a variável independente responsável por este aumento ( $56 \%$ ) com uma correlação fraca, mas significativa $(\mathrm{r}=0,38, \mathrm{p}<0,05, \mathrm{n}=35)$ ao se considerar $\mathrm{S} 2$ $\mathrm{S} 3$. Isto se torna mais intenso quando consideramos as diferenças das médias dos leucócitos entre S1-S3 ( $\mathrm{r}=0,56$, $\mathrm{p}<0,001, \mathrm{n}=35$ ). Não encontramos na literatura qualquer menção a achado semelhante a este e supusemos que isto pudesse representar uma reação ao caráter invasivo do procedimento. A infusão da solução glicosada foi também isolada e relacionada com o aumento dos leucócitos ( $\mathrm{r}=0,49$, $\mathrm{p}<0,05, \mathrm{n}=21$ ) ao se tomar as diferenças entre as médias $\mathrm{S} 2 \mathrm{e}$ S3. Não conseguimos explicar tal achado. De qualquer forma, o conhecimento de que ocorre um aumento dos leucócitos é um achado particularmente relevante, uma vez que a constatação de sua elevação sempre nos leva a suspeitar de algum processo infeccioso.

O íon sódio caiu 2,9\% entre $\mathrm{S} 1$ e S2, tendo sido encontrada forte correlação desse achado com o volume total de solução glicosada infundida durante o procedimento, mas não ao volume do $\mathrm{MC}$ injetado. O efeito dilucional pode explicar este achado. Outros estudos não encontraram alterações significativas neste íon ${ }^{3,6,25} \mathrm{em}$ parte, provavelmente, devido ao seu alto coeficiente de difusão nos leitos capilares e, por outro lado, devido a diferentes rotinas de execu- ção do procedimento em diversos laboratórios. O íon potássio caiu $10 \%$ (S1-S2) e não conseguimos isolar qualquer variável independente para explicar este fato. Levin ${ }^{3} \mathrm{e} \mathrm{col}$ encontraram uma redução significativa nos primeiros $5 \mathrm{~min}$ após uma injeção com um MC de alta osmolalidade.

A diminuição do nível de cálcio (S1-S2) e a identificação do MC como a variável independente responsável por este achado foi uma surpresa, já que este MC é tido como não quelante, uma vez que tem em sua formulação $0,2 \mathrm{mg} / \mathrm{ml}$ de calciedetato dissódico. Não podemos afirmar se a ionicidade do ioxaglato ou uma baixa concentração do anticoagulante foi responsável por este achado. Uma redução transitória no nível de cálcio é esperada ao se usar um MC com alta osmolalidade, iônico e sem cálcio ${ }^{25,26}$.

A osmolalidade nas crianças, comumente entre $287 \pm 6 \mathrm{mOsm} / \mathrm{kg}^{6}$, mostrou um aumento de $2,5 \%$ (S1-S2). Duas horas após, uma redução de 2,3\% (S1-S3). Cumberland ${ }^{5}$ encontrou um aumento da osmolalidade de 1,5\% em 10 crianças após terem recebido uma injeção de ioxaglato. A falta de correlação entre este $\mathrm{MC}$ e as alterações na osmolalidade foi provavelmente devido a vários fatores: o volume de solução glicosada infundida durante o exame $(14,33 \pm 11,48 \mathrm{ml} / \mathrm{kg}) ;$ a medida da osmolalidade só ao fim do procedimento (S2) (duração média de 74,1 $\pm 23,2 \mathrm{~min}$ ); a baixa osmolalidade do ioxaglato $(590,8 \mathrm{mOsm} / \mathrm{kg})$; e a redução do sódio encontrada ao fim do procedimento. No entanto, uma redução de todas variáveis dependentes, ocorrendo ao mesmo tempo, em que havia um aumento da osmolalidade, sugere um efeito dilucional.

A viscosidade do ioxaglato era $5,8 \pm 0,3$, enquanto que a do sangue, em S1 era 3,36 $\pm 0,81$. Desta forma, era de se esperar um aumento da viscosidade ao fim do procedimento. No entanto, o que encontramos foi uma queda de $7,8 \%$ entre S1 e S2. O volume de soro infundido ( $\mathrm{ml} / \mathrm{kg}$ ) esboçou um coeficiente de correlação de 0,39, (NS). Em S3, encontramos um aumento de $25 \%$ na viscosidade. Nenhuma variável independente foi correlacionada com este achado. Já ao se cotejar as diferenças entre as médias de S1 e S3), identificamos o $\mathrm{MC}(\mathrm{ml} / \mathrm{kg})$ com uma correlação indireta $(\mathrm{r}=0,39: \mathrm{p}<0,05)$. Aparentemente o ioxaglato reduz a viscosidade ao reduzir o hematócrito, seu componente principal.

Concluímos para um nível de significância de $\mathrm{p}<0,05$ que houve alterações nas variáveis dependentes-hematócrito, hemoglobina, leucócitos, sódio, potássio, cálcio, viscosidade e osmolalidade e que o ioxaglato foi isolado e relacionado àquelas encontradas no hematócrito/hemoglobina, cálcio e viscosidade, apesar de não explicar totalmente suas variações.

As alterações encontradas nos leucócitos foram, principalmente, relacionadas à duração do procedimento e as do sódio à infusão de solução glicosada. Nenhuma variável independente foi identificada como responsável por alterações na osmolalidade plasmática ou do potássio. 


\section{Referências}

1. Dawson P - Cardiovascular effects of contrast agents. Am J Cardiol 1989; 64: 2E-9E.

2. Krovetz LJ, Shanklin DR, Schiebler GL - Serious and fatal complications of catheterization and angiocardiography in infants and children. Am Heart J 1968; 76: 39-47.

3. Levin AR, Grosman H, Schubert ET, Winchester P, Gilladoga A-Effect of angiocardiography on fluid and electrolyte balance. J Roentgenol 1969; 105: 777-83.

4. Brown R, Rahimtoola SH, Davis GD, Swan HJC - The effect of angiocardiographic contrast medium on circulatory dynamics in man: cardiac output during angiocardiography. Circulation 1965; 31: 234-40.

5. Cumberland DC - Hexabrix a new contrast medium in angiocardiography. $\mathrm{Br}$ Heart J 1981; 45: 698-702.

6. Giammona ST, Lurie PR, Segar WE - Hypertonicity following selective angiocardiography. Circulation 1963; 28: 1096-101.

7. Altman AR, Kahn RE, Borrelli FJ - Fifty per cent sodium diatrizoate for selective angiocardiography in infants complications avoided by use of a low viscosity and low osmolarity contrast medium. Angiology 1967; 18: 150-5.

8. Krovetz LJ, Shanklin DR, Schiebler GL - Serious and fatal complications of catheterization and angiocardiography in infants and children. Am Heart J 1968; 76: 39-47.

9. Krovetz LJ, Grumbar PA, Hardin S, Morgan AV, Schiebler GL - Complications following use of four angiocardiographic contrast media in infants and children. Invest Radiol 1969; 4: 13-8.

10. Srouji MN, Rashkind W - The effect of cardiac catheterization on the acid base status of infants with congenital heart disease. Pediatrics 1969; 75: 943-51.

11. Lachlan $\mathrm{H}$ - Biochemical and other changes occurring in infants during angiocardiography. Proc Roy Soc Med 1970; 63: 10-3.

12. Leriche H, Demanton S, Losay J - Cardiopathies congénitales et produits de contraste. Essais d'un nouvel opacifiant. Coeur 1981; 12: 261-4.

13. Nikula E, Kiviniitty K - Cytogenic effects of cardioangiography on blood lymphocytes in children and in vitro effects of contrast medium and low dose radiation. Acta Oncol. 1987; 26: 69-74.

14. Saito H, Kimura K, Takamiya M et al - Comparison of ionic and nonionic low osmolar contrast media in coronary arteriography a cross- over study in children. Invest Radiol 1988; 23: 910-3.

15. Rubin CM, Ogilvie BC, Keeton BR - Comparison of low-osmolar contrast media in paediatric cardiac angiography. Br J Radiol 1987; 60: 133-5.

16. Gliech V, Goldner B, Gola G, Munster W, Kothe K - A double-blind randomized comparative study of iopromide and amidotrizoate in the angiocardiography of infants and young children with congenital heart defects. Radiol Diagn Berl 1989; 30: 328-32.

17. Amiel M, RevelD-Pediatric angiocardiography. Randomized, controlled study of 2 iodinated contrast media: iopromide 300 and ioxaglate $320 \mathrm{mgi} / \mathrm{ml}$. Ann Radiol Paris 1989; 32: 336-8.

18. Pelech NA, Allard SM, Hurd RT, Giddins NG, Collins GF - A comparison of iohexol and diatrizoate-meglumine in children undergoing cardiac catheterization. Invest Radiol 199; 26: 665-70.

19. Hentschel M, Gildein P, Brandis M, Zimmerhackl LB - Endothelin (ET-1) is involved in the contrast media induced nephrotoxicity in children with congenital heart disease. Clin Nephrol 1995; 43(suppl 1): S12-15.

20. Kavukcu S, Tavli V, Fadiloglu M, Akhunlar H, Oran B, Akcoral A - Urinary enzyme changes in children undergoing cineangiographic evaluation using iopromid. Int Urol Nephrol. 1995; 27 : 131-5.

21. Rossignol AM, Lusson JR, Chantepie A, Losay J - Safety and efficacy of xenetix, a new iodinated contrast agent, in pediatric angiocardiography. Acta Radiol 1996; 400(suppl): 81-4.

22. Tschäppeler H- Ioxaglate as contrast medium in pediatric urography. Eur Soc Ped Radiol 1980; 24: 105-8

23. Daniel MK, Bennett B, Dawson AA, Rawles JM - Haemoglobin concentration and linear cardiac output, peripheral resistence, and oxygen transport. Br Med J 1986; 292: 923-6.

24. Hirshfeld JW, Laskey W, Martin JL, Groh WC, Untereker W, Wolf GL-Hemodynamic changes induced by cardiac angiography with ioxaglate: comparison with diatrizoate. J Am Coll Cardiol 1983; 2: 954-7.

25. Caufield JB, Zir L, Harthorne JW - Blood calcium levels in the presence of arteriographic contrast material. Circulation 1975; 52: 119-23.

26. Morris TW, Sahler LG, Fischer HW - Calcium binding by radiopaque media. Invest Radiol 1982; 17: 501-5. 